\title{
Evaluation of Sequential Extraction for Speciation of Trace Metals in Model Soil Containing Natural Minerals and Humic Acid
}

\author{
Shan Xiao-Quan* and Chen Bin \\ Research Center for Eco-Environmental Sciences, Academia Sinica, P.O. Box 2871, Beijing 100085, China
}

\begin{abstract}
A model soll syntheelzed wh several natural minerals and humic acid is used to evaluate the sequentlal extraction for speciation analyels of trace elements in soll. Although the recommended sequentlal extractants are able to bring the Individual geochemical phases into solution at the expertmentally defined stage, none of the extractants ls completely speclitic and efficlent. Various proportions of metals released at exchangeable, carbonate-bound, Fe-Mn oxlde-bound, organic-bound fractlons are readeorbed onto the other solld geochemlcal phases during sequentlal extraction. However, It is difflcult to quantify the extent of readsorption and/or redistribution for the Individual element and for the Individual geochemical phase.
\end{abstract}

Sequential extraction techniques have been widely used for the speciation analysis of major and trace elements in soils and sediments. Due to the growing interests in the development and application of the sequential extraction techniques, several reviews appeared in the literature..$^{1-4}$ Several different sequential extraction procedures have been developed. . $^{5-18}$ Most include up to five extractants: cationexchange extractants, carbonate-dissolving extractants, acidic reducing extractants, extractants that release organic- and sulfide-bound metals, and strong acidic extractants for dissolving silicates or minerals that have not been attacked by the milder reagents. It must be pointed out that the most widely recognized sequential extraction is Tessier's method,? which has been frequently used. 8,12 Miller et al. ${ }^{13}$ examined the order of extraction for key steps in the sequential extraction and proposed a nine-step sequential method to characterize trace metals in agricultural polluted and wasteamended soils. In order to simplify the sequential extraction method, Chao and Sanzolone ${ }^{15}$ divided soil selenium into immediate and potential impact categories and recommended a two-step extraction procedure.

* To whom all correspondence should be addressed.

(1) Pickering, W. F. CRC Crit. Rev. Anal. Chem. 1981, 12, 233.

(2) Salomons, W.; Forstner, U. Environ. Technol. Lett. 1980, 1, 506.

(3) Welte, B.; Bles, N.; Montiel, A. Environ. Technol. Lett. 1983, 4, 79.

(4) Forstner, U. Fresenius Z. Anal. Chem. 1983, 17, 604.

(5) Lavkulich, L. M.; Wiens, J. H. Soil Sci. Soc. Am. Proc. 1970, 34, 755.

(6) Chao, T. T. Soil Sci. Soc. Am. Proc. 1972, 36, 764

(7) Tessier, A.; Campbell, P. G. C.; Bisson, M. Anal. Chem. 1979, 51, 844.

(8) Harrison, R. M.; Laxen, D. P.H.; Wilson, S. J. Environ. Sci. Technol. $1981,15,1378$.

(9) Shuman, L. M. Soil Sci. Soc. Am. J. 1982, 46, 1099.

(10) Chao, T. T.; Zhou, L. Soil Sci. Soc. Am. J. 1983, 47, 225.

(11) Shuman, L. M. Soil Sci. Soc. Am. J. 1983, 47, 656.

(12) Maher, W. A. Bull. Environ. Contam. Toxicol. 1984, 32, 339.

(13) Miller, W. P.; Martens, D. C.; Zelazny, L. W. Soil Sci. Soc. Am.

J. 1986, 50, 598 .

(14) Singh, J. P.; Karwasra, S. P. S.; Singh, M. Soil Sci. 1988, 146, 359.

(15) Chao, T. T.; Sanzolone, R. F. Soil Sci. Soc. Am. J. 1989, 53, 385.

(16) Sharpley, A. N. Soil Sci. Soc. Am. J. 1989, 53, 1023.

(17) Griffin, T. M.; Rabenhorst, M. C.; Fanning, D. S. Soil Sci. Soc. Am. J. 1989, 53, 1010.

(18) Kodama, H.; Wang, C. Soil Sci. Soc. Am. J. 1989, 53, 526.
Although various sequential extraction approaches were recommended in the literature, these methods suffered from nonselectivity of extractants and trace element redistribution among phases during extraction. Guy et al..$^{19}$ used bentonite, manganese oxide, and humic acid spiked with copper and lead to evaluate the extraction methods, and the results indicated that the chemical extraction procedures were unable to determine unequivocally the sites of the adsorbed metals in sediments. The intercomponent interferences prevented $100 \%$ recoveries of the doped metals. Tipping et al..$^{20}$ observed the direct evidence of redistribution when manganese oxide in a mine wall deposit was selectively separated from iron oxide by using hydroxylamine. Electron microscopy analysis before extraction indicated that lead was in the manganese phase, but none was found in the iron phase. After extraction, lead was present in the iron phase. The reason for the transfer of a large amount of lead from manganese to iron oxide was ascribed to the adsorption of lead on the remaining iron oxide during hydroxylamine treatment. Kheboian and Bauer ${ }^{21}$ criticized the accuracy of Tessier's sequential extraction for metal speciation by using model aquatic sediments. Trace elements of lead, zinc, copper, and nickel were doped into each phase by coprecipitation or adsorption. Then, the model aquatic sediments were successively treated with a five-step extraction procedure under the conditions recommended by Tessier et al. ${ }^{7}$ Generally, none of the trace elements were removed at the stage predicted according to Tessier's method. This was mainly due to the elemental redistribution.

The advantages of using purified commercially available illite, silicate gel, and humic acid and other pure chemical compounds and of using doped trace elements in each phase are the simplicity and ease of understanding the behavior of trace elements during sequential extraction. However, soils and sediments are a complex mixture of mineral fragments and decomposition products, reflecting the nature of the original base rock, the degree of degradation and leaching introduced by weathering cycles, and the influence of external inputs such as plant debris or contamination introduced by human activities. Therefore, the properties of the model aquatic sediments are unlikely to be sufficiently representative of real sediments. Tessier and Campbell ${ }^{22}$ argued the validity of the approach and experimental problems associated with the methods used by Kheboian and Bauer and some others. The main drawback of the model sediment as prepared by mixing a phase doped with a trace metal with other phases not doped with that metal is nonequilibrium distribution of trace metals among various solid phases; in other words, the model sediment is biased toward trace metal redistribution.

The purpose of the present work is to study the merit of Tessier's method for speciation analysis of trace metals in

(19) Guy, R. D.; Chakrabarti, C. L.; Mebain, D. C. Water Res. 1978, 12,21

(20) Tipping, E.; Hetherington, N. B.; Hilton, J.; Thompson, D. W.;

Bowles, E.; Hamilton-Taylor, J. Anal. Chem. 1985, 57, 1944.

(21) Kheboian, C.; Bauer, C. F. Anal. Chem. 1987, 59, 1417

(22) Tessier, A.; Campbell, P. G. C. Anal. Chem. 1988, 60, 1475. 
Table I. Elemental Content in Minerals and Humic Acida

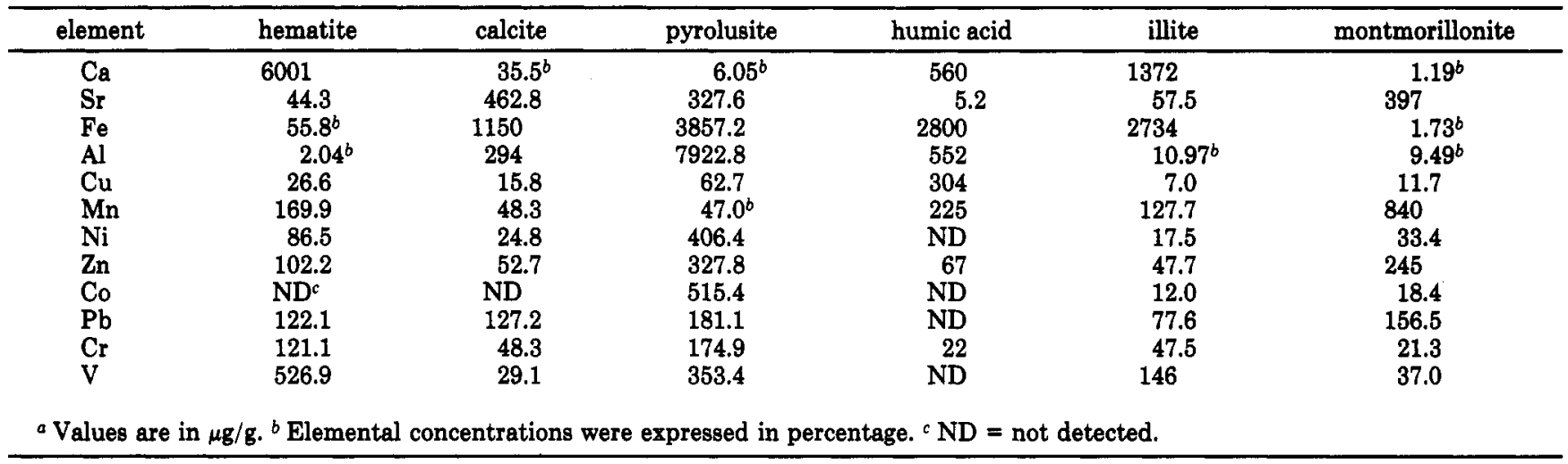

soil using a model soil consisting of several natural minerals and humic acid, which is expected to have similar properties to that of the corresponding components of the real soils. The readsorption and redistribution of the released trace metals in the solution onto the solid phases during extraction is also investigated.

\section{EXPERIMENTAL SECTION}

Apparatus. A Model Y-2 X-ray diffractometer (Dandong Instrumental Factory, China) and Model $35 \mathrm{C}$ scanning electron microscopy (JEOL, Japan) equipped with a Model 9100 energy dispersive X-ray analyzer (EDAX, Philips) were used for the characterization of solid natural minerals. The Jarrell-Ash Model $1155 \mathrm{~V}$ AtomComp was used for the concentration determinations of major and trace elements in the extraction solutions.

Materials. Natural minerals such as hematite, calcite, illite, pyrolusite, and montmorillonite were purchased from Geological Academy. The minerals were ground and sieved through a 160$\mu \mathrm{m}$ sieve. No further purification was made. The contents of montmorillonite, illite, hematite, pyrolusite, calcite, and humic acid in the model soil were $40,40,5,5,5$, and $5 \%$, respectively. Humic acid was separated from the soil according to the procedure of International Humic Substances Society. ${ }^{23}$ The soil used for the separation of humic acid was collected from the surface horizon with the darkest color (highest organic matter content) in Heilongjiang Province, China. The sample was air-dried and crushed to pass through a $2-\mathrm{mm}$ sieve. Soil description was performed according to the American Classification System. The soil was mollisol, sandy-silty, and mixed. It had a $\mathrm{pH}$ of 7.0 (1:2.5 soil/water suspension), $33.5 \%$ clay, $59.2 \%$ silt, and $7.3 \%$ sand. The contents of $\mathrm{C}, \mathrm{H}, \mathrm{N}, \mathrm{O}$, and $\mathrm{S}$ in the humic acid were $53.5,4.8,3.8,37.7$, and $1.0 \%$, respectively. The ash content of humic acid was $3.40 \%$. The concentrations of trace elements in the minerals and humic acid were determined by the ICP-AES method after the samples were dissolved by HF and aqua regia. The standard solutions for the calibration of ICP-AES determinations were prepared by dissolving adequate amounts of specpure metals or compounds in appropriate concentrations of mineral acids, and the solutions were then diluted with deionied quartz-distilled water. All other chemicals used in the present study were of analytical reagent grade.

Extraction. The procedure used for the sequential extraction was basically the same as that recommended by Tessier et al.? with a small modification. Duplicate $0.100-\mathrm{g}$ subsamples were taken from each mineral and transferred to $15-\mathrm{mL}$ acid-washed polycarbonate centrifuge tubes and extracted simultaneously with $12 \mathrm{~mL}$ of the extractant solution following the Tessier's method After centrifugation, the supernatant was removed into a $50-\mathrm{mL}$ volumetric flask by pipeting for analysis. The residue was rinsed with $1 \mathrm{~mL}$ of water; the washing was combined with the supernatant. Then, the residue was treated with the next reagent in the sequence. The sequential extraction procedure was briefly as follows. Step 1: $1 \mathrm{M} \mathrm{MgCl}_{2}$ (pH 7), $1 \mathrm{~h}$, room temperature, continuous agitation. Step 2: $1 \mathrm{M}$ sodium acetate (pH 5), $5 \mathrm{~h}$,

(23) Wershaw, R. L.; Pinckney, D. J.; Llaguno, E. C.; Vicente-Beckett V. Anal. Chim. Acta 1990, 232, 31. room temperature, continuous agitation. Step 3: $0.04 \mathrm{M} \mathrm{NH}_{2-}$ $\mathrm{OH} \cdot \mathrm{HCl}$ in $25 \%$ acetic acid, $5 \mathrm{~h}, 96^{\circ} \mathrm{C}$, some agitation. Step 4: $0.02 \mathrm{M} \mathrm{HNO}_{3}$ and $30 \% \mathrm{H}_{2} \mathrm{O}_{2}, 2 \mathrm{~h}, 85^{\circ} \mathrm{C}$, some agitation; then additional $\mathrm{H}_{2} \mathrm{O}_{2}, 3 \mathrm{~h}, 85^{\circ} \mathrm{C}$, some agitation; cooled, then $3.2 \mathrm{M}$ ammonium acetate in $20 \% \mathrm{HNO}_{3}, 0.5 \mathrm{~h}$, room temperature, continuous agitation. Fraction 5 was treated differently from Tessier's method. The residue was transferred into a $30-\mathrm{mL}$ Teflon crucible with water and heated gently to near dryness on a hot plate. After addition of $2 \mathrm{~mL}$ of $\mathrm{HF}$ and $2 \mathrm{~mL}$ of aqua regia, the crucible was sealed in a stainless steel bomb and heated at $180^{\circ} \mathrm{C}$ for $6 \mathrm{~h}$. After the bombs were cooled down to the room temperature, the crucible was taken out of the bomb and the mixture was heated on a hot plate to near dryness. Finally, an adequate volume of $1 \mathrm{M} \mathrm{HNO}_{3}$ was added to dissolve the residue, the solution was transferred to a $50-\mathrm{mL}$ volumetric flask, and it was diluted to the mark with water.

For model soil, duplicate $0.50 \mathrm{-g}$ subsamples were taken, and the same procedure was used for the sequential treatment.

In the present study the readsorption and redistribution were examined by comparing the metal partitioning of individually characterized natural minerals with that of the model soil.

Analysis. For X-ray diffraction analysis, samples were mounted on glass slides and analyzed with a $\mathrm{Cu}$ tube and $\mathrm{Ni}$ filter. For scanning electron microscopy inspection, particulate materials were attached to brass stubs and were sputter-coated with a thin layer of $C$.

Elemental concentrations in the extract solutions were determined simultaneously by ICP-AES. The operating conditions for the determinations were optimized. The corrections for background shift and spectral interferences were performed. The accuracy of determinations was examined by using NIST SRM 1645 river sediment and 1646 estuarine sediment, and a good agreement was achieved between the results obtained by ICPAES determinations and the certified values.

\section{RESULTS AND DISCUSSION}

Characterization of Natural Minerals. Generally, soil components include carbonates; sands; silt; hydrous oxides of $\mathrm{Fe}, \mathrm{Al}$, and $\mathrm{Mn}$; clay minerals, and organic matter. ${ }^{1}$ The natural minerals selected for the model soil are considered to be the representatives of soil components and corresponded to the chemical descriptions assigned to each stage of Tessier's method. Under the considerations calcite, hematite, pyrolusite, illite, montmorillonite, and humic acid were selected for the model soil components. The crystal morphology of the selected minerals was analyzed by X-ray diffraction.

The concentrations of major and trace elements in the minerals were determined by ICP-AES (Table I). Since the concentrations of trace elements were below $1 \%$ (the detection limit of X-ray diffraction analysis), significant changes in $\mathrm{X}$-ray spectra were unlikely. Scanning electron microscopy was unable to identify the distribution of trace elements in the minerals either.

Extraction Behavior of Trace Elements in the Single Mineral Phase. Tessier's sequential extraction was per- 


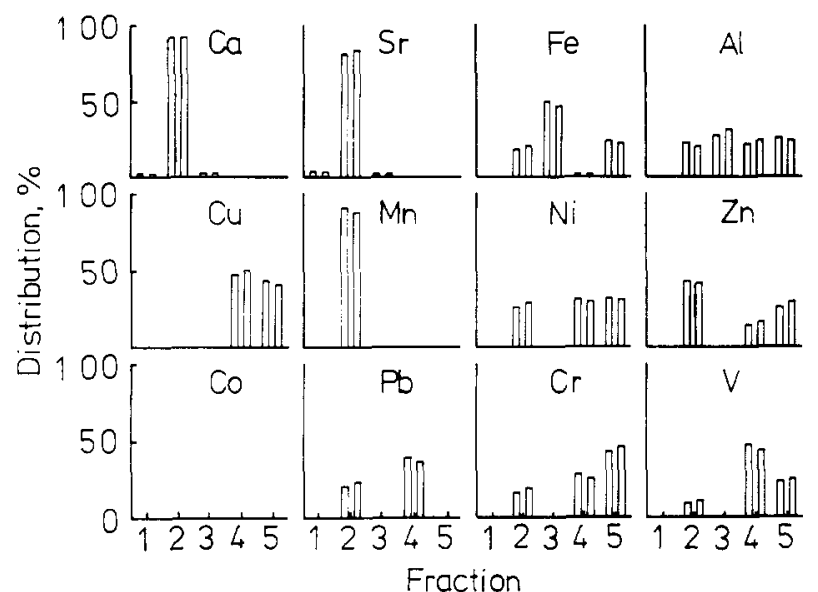

Floure 1. Sequential extraction results for calcite. Numbers on the horizontal axls correspond to the sequential extraction steps. Bar helights are percentages with respect to the total element concentration present. Two bars at each stage represent two separate mineral samples.

formed for the single mineral phase and model soil. It must be pointed out that the so-called single mineral phase is not solely single phase, it contains other minor mineral phases which cannot be directly identified by X-ray diffraction analysis before the major phases are brought into solution. The extraction behavior of trace elements in the phases was discussed below.

Calcite. Figure 1 gives the extraction results for calcite. As can be seen from the figure, no significant amounts of major and trace elements were removed at step 1, and more than $90 \%$ of $\mathrm{Ca}, \mathrm{Sr}$, and $\mathrm{Mn}$ was extracted at step 2 . Calcium found in extract 1 was probably due to the early dissolution of calcite ${ }^{21}$ or due to the presence of more soluble gypsum $\left(\mathrm{CaSO}_{4} \cdot 2 \mathrm{H}_{2} \mathrm{O}\right) .{ }^{24}$ The $96 \%$ strontium recovery at stage 2 can be explained by the fact that the two minerals of strontium are celestite $\left(\mathrm{SrSO}_{4}\right)$ and strontianite $\left(\mathrm{SrCO}_{3}\right)$, and traces of strontium occur in nearly all limestone. ${ }^{25}$ Rhodochrosite is one of the most common ores of manganese, ${ }^{26}$ and $90 \% \mathrm{Mn}$ was extracted at step 2. The presence of $\mathrm{MnCO}_{3}$ in calcite was supported by Prohic and Kniewald. ${ }^{27}$ The ionic radii of $\mathrm{Mn}^{2+}$ and $\mathrm{Ca}^{2+}$ ions are 0.80 and $0.99 \AA$, respectively. The $\mathrm{Mn}^{2+}$ ion can substitute $\mathrm{Ca}^{2+}$ ion in the crystalline lattice of calcite, giving up to $40 \%$ of $\mathrm{MnCO}_{3}{ }^{27}$

The residue left after step 2 extraction was identified as dolomite $\left[\mathrm{CaMg}\left(\mathrm{CO}_{3}\right)_{2}\right.$ ] by X-ray diffraction analysis which cannot be brought into solution by sodium acetate at $\mathrm{pH} 5$. This phenomenon was also observed by Prohic and Kniewald. ${ }^{27}$ According to the elemental concentration determinations, iron was the richest concomitant in calcite (Table I). Amorphous or crystalline iron oxide may coexist. Since $3.4 \%$ of $\mathrm{Ca}$ was determined at step 3 , dolomite was decomposed by $\mathrm{NH}_{2} \mathrm{OH} \cdot \mathrm{HCl}$ plus HOAc. According to Tessier et al., amorphous iron hydroxide should be brought into solution at step 3 and crystalline iron oxide should not. In the present case, $49 \%$ of iron was released at stage 3 . This indicated that amorphous iron oxides coexisted in calcite. Additionally, $30 \%$ of $\mathrm{Al}$ was also released at stage 3; this indicated that part of the aluminum was associated with amorphous iron oxide. It

(24) Bohn, H. L.; Mcneal, B. L.; O'Connor, G. A. Soil Chemistry; John Wiley \& Sons, Inc.: New York, 1979; p 131

(25) Goodenough, R. D.; Stenger, V. A. Magnesium, Calcium, Strontium, Barium and Radium. In Comprehensive Inorganic Chemistry Bailar, J. C., Emeleus, H. J., Nyholm, S. R., Trotman-Dickenson, A. F. Eds.; Pergamon Press: Oxford, 1973; Vol. 1, p 589.

(26) Kemmitt, R. D. W. Manganese. In Comprehensive Inorganic Chemistry; Bailar, J. C., Emeleus, H. J., Nyholm, S. R., TrotmanDickenson, A. F., Eds.; Pergamon Press: Oxford, 1973; Vol. 3, p 771.

(27) Prohic, E.; Kniewald, G. Mar. Chem. 1987, 22, 279.

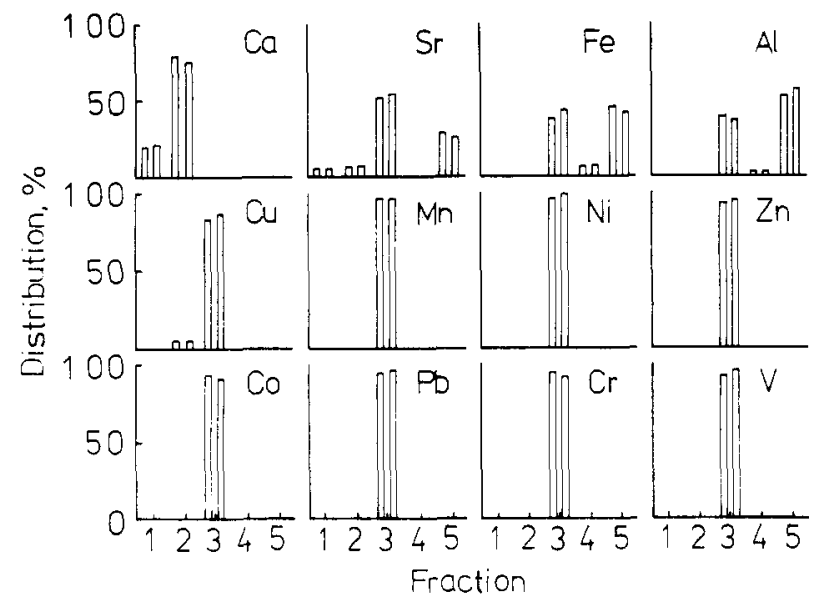

Fioure 2. Sequential extraction results for pyroluslte. Same legend information as that given for Figure 1.

should also be pointed out that no other trace elements were detected at this stage. However, certain amounts of $\mathrm{Cu}, \mathrm{Pb}$, $\mathrm{Zn}, \mathrm{Ni}, \mathrm{Al}, \mathrm{Cr}$, and $\mathrm{V}$ were determined at step 4. The reason for the detection of trace elements was ascribed to the presence of humic acid in calcite. Normally, humic acid forms various complexes with $\mathrm{Cu}, \mathrm{Pb}, \mathrm{Zn}, \mathrm{Ni}, \mathrm{Cd}$, and $\mathrm{V} .{ }^{28}$ It should also be pointed out that parts of trace $\mathrm{Al}, \mathrm{Ni}, \mathrm{Zn}, \mathrm{Cu}, \mathrm{Cr}$, and $\mathrm{V}$ were detected at step 5 . These elements were expected to be associated with the crystalline lattice of iron phases such as in hematite, which would be discussed in the latter section. Therefore, crystalline iron oxide was dissolved at step 5, and trace $\mathrm{Al}, \mathrm{Cu}, \mathrm{Ni}, \mathrm{Zn}, \mathrm{Pb}, \mathrm{Cr}$, and $\mathrm{V}$ were detected at this stage.

Pyrolusite. Figure 2 gives the extraction behavior of major and trace elements in pyrolusite. Calcium was expected to be adsorbed on the surface of pyrolusite or to be present as calcium carbonate. Therefore, it was removed at steps 1 and 2, respectively. Pyrolusite was decomposed almost exclusively in the appropriate stage according to the method of Tessier et al. More than $90 \%$ of $\mathrm{Cu}, \mathrm{Ni}, \mathrm{Zn}, \mathrm{Co}, \mathrm{Pb}, \mathrm{Cr}$, and $\mathrm{V}$ was also removed at step 3 . These elements were bound to manganese oxide. However, only part of $\mathrm{Sr}, \mathrm{Fe}$, and Al were brought into solution at this stage. The residue from step 3 was identified as quartz, barite, hematite, illite, and kaolinite by X-ray diffraction analysis. Therefore, the detection of $\mathrm{Fe}$ and $\mathrm{Al}$ at stages 4 and 5 was easily understood. The reason for strontium at step 5 was ascribed to the presence of strontium as an impurity in quartz, illite, and hematite. On the basis of the above study, it can be concluded that hydroxylamine hydrochloride solution is the most desirable extractant for manganese oxides. ${ }^{9}$

Hematite. Chao and Zhou ${ }^{10}$ compared the extraction behavior of five extractants for selective dissolution of amorphous iron oxides from soils and sediments and indicated that $0.25 \mathrm{M} \mathrm{NH}_{2} \mathrm{OH} \cdot \mathrm{HCl}-0.25 \mathrm{M} \mathrm{HCl}$ was chosen as the most desirable extractant for amorphous iron oxides from soils because only $1 \%$ of iron was removed from crystalline iron oxide by the hydroxylamine hydrochloride solution. Hematite is a well-crystallized iron oxide, and the present study confirms this conclusion. Figure 3 depicts the extraction behavior of hematite. As can be seen, only 1.9 and $0.5 \%$ of total iron were removed at stages 3 and 4 , respectively, and $94 \%$ of iron was decomposed at step 5 . The amounts of $\mathrm{Ca}, \mathrm{Cu}, \mathrm{Cr}, \mathrm{Sr}$, $\mathrm{Zn}, \mathrm{Al}, \mathrm{V}, \mathrm{Pb}$, and $\mathrm{Ni}$ removed at step 5 were found to be in the range of $68-96 \%$. The results verified that these elements were mainly associated with the crystalline iron oxides. The reason for the removal of trace elements at the previous stages was unclear. It might be due to the presence of other discrete

(28) Beveridge, A.; Pickering, W. F. Water, Air Soil Pollut. 1980, 14, 171 


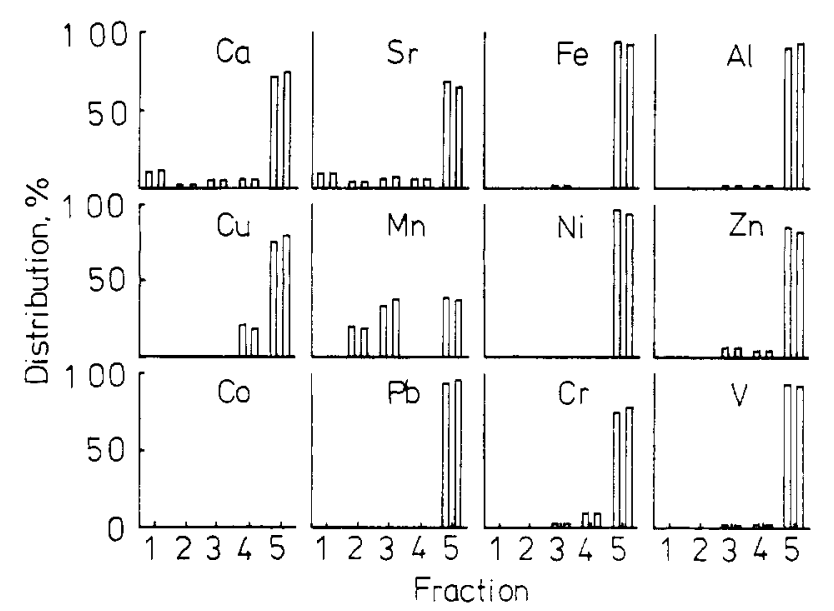

Figure 3. Sequential extractlon results for hematite. Same legend intormation as that given for Figure 1.

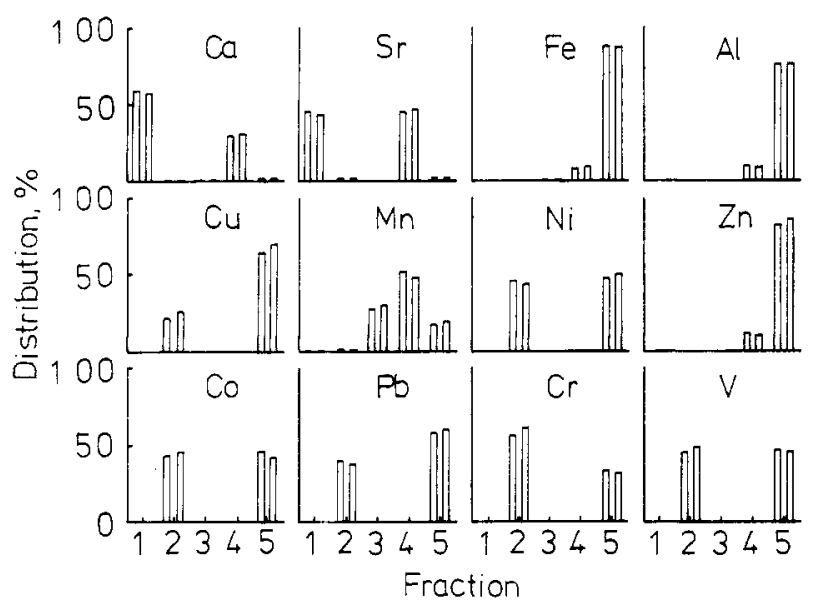

Flgure 4. Sequentlal extraction results for montmorillonite. Same legend information as that given for Figure 1.

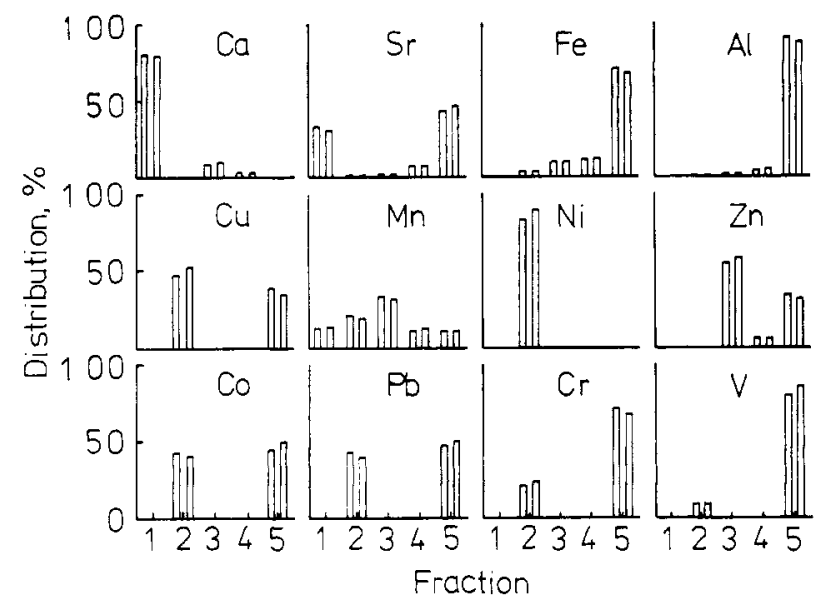

Figure 5. Sequentlal extraction results for illite. Same legend information as that given for Figure 1.

geochemical phases or due to the adsorption of the elements on the surface sites of crystalline iron oxides.

Montmorillonite and Illite. Montmorillonite is 2:1 layer silicates. In montmorillonite $\mathrm{Al}^{3+}$ is the major and $\mathrm{Mg}^{2+}$ is the minor, octahedral cation. Soil montmorillonites often exhibit imperfect isomorphic substitution, with some $\mathrm{Al}^{3+}$ substituting for $\mathrm{Si}^{4+}$ in the tetrahedral sheet and with $\mathrm{Fe}^{2+}$ (as well as $\mathrm{Mg}^{2+}$ ) substituting for $\mathrm{Al}^{3+}$ in the octahedral sheet. Illite may be either dioctahedral or trioctahedral. Figures 4 and 5 elucidate the elemental partitioning. As can be seen, aluminum and iron were mainly removed at step 5 . The reasons for the detection of a small amount of $\mathrm{Fe}, \mathrm{Al}$, and $\mathrm{Mn}$

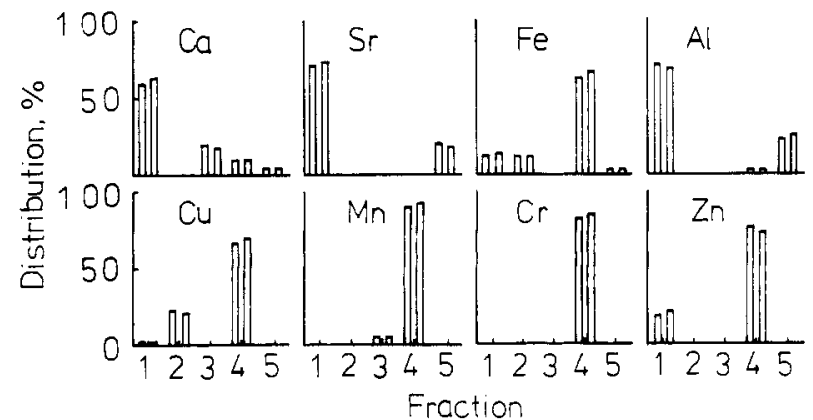

Fipure 6. Sequential extraction results for humic acid. Same legend information as that given for Figure 1.

in steps 3 and 4 were ascribed to the decomposition of oxides of $\mathrm{Fe}, \mathrm{Al}$, and $\mathrm{Mn}$ by hydroxylamine hydrochloride or acetic acid as well as the degradation of humic acid by hydrogen peroxide. It should be pointed out that certain amounts of $\mathrm{Cu}, \mathrm{Co}, \mathrm{Pb}, \mathrm{Cr}$, and $\mathrm{V}$ were removed at step 2 from montmorillonite and illite. The reason for this was probably that at step 1 the neutral $1 \mathrm{M} \mathrm{MgCl}_{2}$ did not completely desorb the specificially adsorbed trace elements; lowering the $\mathrm{pH}$ to 5.0 in step 2 would then release the remaining adsorbed trace elements. However, calcium concentration in the montmorillonite and illite were much greater than other trace elements (Table I); there was no calcium detected at step 2. Therefore, the trace elements cannot be considered as the carbonate-bound fraction. We would prefer to assume that the trace elements were adsorbed onto the surface of montmorillonite and illite.

Humic Acid. Since hydrogen peroxide may solubilize oxides of $\mathrm{Fe}, \mathrm{Mn}$, and $\mathrm{Al}$, sodium hypochlorite was recommended as an alternative to organic fraction extractant. ${ }^{5,11}$ However, $\mathrm{H}_{2} \mathrm{O}_{2}$ is still used for the organic fraction extraction after the oxides have been brought into solution. Figure 6 depicts the partitioning patterns of trace elements in the humic acid separated from soil. Dominant amounts of Fe, $\mathrm{Cu}, \mathrm{Zn}, \mathrm{Mn}$, and $\mathrm{Cr}$ were removed at step 4. This demonstrated that these metals were bound with humic acid by forming stable complezes. However, $\mathrm{Ca}, \mathrm{Sr}$, and $\mathrm{Al}$ were mainly present as an exchangeable fraction. The reason for this was probably due to the presence of some inorganic minerals as impurities to humic acid.

Extraction Behavior of Trace Elements in the Model Soil. There were some arguments in the literature about the readsorption or redistribution of the released elements among phases during sequential extraction. This was briefly described in the introductory section. The approaches used for the study of readsorption and/or redistribution were the model system prepared by mixing a phase doped with a trace metal with other phases not doped with that metal and standard additions. Due to the inherently unstability of the model system and much higher concentrations of trace elements added than the natural concentration found in the sediments, the model system and standard addition methods were biased toward metal redistribution.

In order to evaluate the analytical merit of the sequential extraction for speciation analysis of trace elements in soils, in other words, to evaluate the possibility of readsorption and/or redistribution of the released metals among the remaining phases during sequential extraction, a model soil was used in the present study by mixing various natural minerals and humic acid. It must be pointed out that the model soil used in the present study is different from the model sediments used by Kheboian and Bauer. ${ }^{21}$ On the basis of the above experiments, the conclusion can be reached that each natural mineral is not really a single geochemical phase and that it always contains other minor geochemical 
Table II. Comparison of Experimentally Extracted Metal Concentrations from the Model Soil with the Calculated Values ${ }^{\star}$

\begin{tabular}{|c|c|c|c|c|c|c|c|c|c|c|}
\hline \multirow[b]{2}{*}{ element } & \multicolumn{2}{|c|}{ step 1} & \multicolumn{2}{|c|}{ step 2} & \multicolumn{2}{|c|}{ step 3} & \multicolumn{2}{|c|}{ step 4} & \multicolumn{2}{|c|}{ step 5} \\
\hline & $\begin{array}{l}\text { exptl } \\
\text { value }\end{array}$ & $\begin{array}{l}\text { calcd } \\
\text { value }\end{array}$ & $\begin{array}{l}\text { exptl } \\
\text { value }\end{array}$ & $\begin{array}{l}\text { calcd } \\
\text { value }\end{array}$ & $\begin{array}{l}\text { exptl } \\
\text { value }\end{array}$ & $\begin{array}{l}\text { calcd } \\
\text { value }\end{array}$ & $\begin{array}{l}\text { exptl } \\
\text { value }\end{array}$ & $\begin{array}{l}\text { calcd } \\
\text { value }\end{array}$ & $\begin{array}{l}\text { exptl } \\
\text { value }\end{array}$ & $\begin{array}{l}\text { calcd } \\
\text { value }\end{array}$ \\
\hline $\mathrm{Ca}$ & 4776 & 5688 & 17965 & 18818 & 1600 & 756 & 1280 & 1708 & 1565 & 359 \\
\hline $\mathrm{Sr}$ & 85.7 & 95.2 & 24.2 & 27.6 & 7.6 & 10.6 & 8.3 & 75.3 & 92.3 & 21.9 \\
\hline $\mathrm{Fe}$ & $\mathrm{ND}^{b}$ & 18.8 & 11.2 & 72.8 & 186 & 795 & 1019 & 1016 & 33098 & 33205 \\
\hline $\mathrm{Al}$ & ND & 19.4 & 117.7 & 346.9 & 251 & 634 & 3336 & 4898 & 77500 & 76507 \\
\hline $\mathrm{Cu}$ & ND & 0.42 & ND & 6.8 & 0.96 & 2.1 & 12.7 & 13.0 & 13.0 & 6.5 \\
\hline $\mathrm{Mn}$ & 10.0 & 9.8 & 22.7 & 43 & 11800 & 22471 & 10117 & 97 & 566 & 74 \\
\hline $\mathrm{Ni}$ & ND & ND & 6.3 & 13.6 & 9.9 & 20.7 & 15.3 & 0.4 & 12.5 & 8.4 \\
\hline $\mathrm{Zn}$ & ND & 0.55 & $\mathrm{ND}$ & 1.3 & 11.1 & 26.4 & 18.2 & 15.5 & 88 & 80.4 \\
\hline Co & ND & ND & ND & 6.3 & 12.3 & 24.0 & 14 & 0.3 & 11 & 6.1 \\
\hline $\mathrm{Pb}$ & ND & ND & 7.6 & 33.6 & 17.3 & 8.7 & 16.8 & 2.4 & 79 & 65.0 \\
\hline $\mathrm{Cr}$ & ND & ND & 3.2 & 12.3 & 4.8 & 7.5 & 8.6 & 2.3 & 28.5 & 25.8 \\
\hline $\mathrm{V}$ & ND & ND & 4.6 & 15.3 & 7.7 & 17.5 & 15.1 & 0.7 & 95.0 & 90.0 \\
\hline
\end{tabular}

phases. In addition, the humic acid used in the model soil is separated from the surface soil with the knowledge of its origin and chemical characteristics. Therefore, the major and trace elements would have already been distributed among the various phases. Obviously, this is a distinct advantage of the present model soil over the others reported in the literature.

To study the readsorption that occurred during the sequential extraction, a comparison was made between the experimental fractions of major and trace elements removed at each step from the model soil and the calculated values obtained by summing the concentrations of various chemical forms of the so-called single natural mineral based on the previous experiments. All the results are given in Table II. It can be clearly seen that some trends in the readsorption and redistribution are quite evident.

In order to explain clearly the readsorption and redistribution of the released trace elements in the solution onto the remaining solid phases, the discussion was first concerned with the partitioning of the representative elements of the particular natural mineral at the appropriate steps experimentally defined by Tessier et al.

According to the composition of the model soil, the concentration of calcium in each component, and the calcium partitioning from each natural mineral shown in Figures $1-6$, the ratios of the calcium contribution from calcite (Figure 1) and pyrolusite (Figure 2) to the total calcium released from the model soil at step 2 were 86 and $12 \%$, respectively, and the contribution of calcium released at this step from other phases was quite negligible. In comparing the experimental value of calcium to the calculated one at step 2, the difference between the two values was not significant considering the possible experimental errors involved in such complicated sequential extraction procedures. Therefore, it seems that no readsorption and redistribution of calcium occurred at step 2. As far as the differences of calcium between the experimental and calculated values are concerned, that part of the exchangeable calcium at step 1 was readsorbed onto the oxides of manganese and iron as well as onto the clay minerals. Probably, part of the calcium adsorbed on humic acid was also transferred into clay minerals. When the ironmanganese oxides were decomposed by the appropriate extractants, the readsorbed calcium was again transferred into solution. Obviously, the readsorbed calcium by clay minerals was also dissolved by strong acid attack method. Therefore, greater experimental values than the calculated ones for calcium were observed at steps 3 and 5 . This indicated that readsorption and redistribution of calcium occurred at steps $1,3,4$, and 5 .

Theoretically, amorphous iron oxides are easily decomposed by $0.04 \mathrm{M} \mathrm{NH}_{2} \mathrm{OH} \cdot \mathrm{HCl}$ in $25 \%$ acetic acid, and the crystalline iron oxides are not. The iron contribution from hematite (Figure 3), illite (Figure 5), montmorillonite (Figure 4), and pyrolusite (Figure 2) to the total iron of the model soil released at step 3 was $67,14,6$, and $10 \%$, respectively. If there was no readsorption and redistribution of iron at this step, the experimental value should be similar to the calculated one. However, this was beyond the expectation, the former was only $23.4 \%$ of the latter. It indicated that certain amounts of iron were readsorbed onto the remaining solid phases, but no increase in the experimental values of iron at steps 4 and 5 was obtained. This was probably due to only a small amount of iron in the amorphous oxides, 2 orders of magnitude smaller than iron detected at step 5. Similarly, manganese released at step 3 should predominantly come from pyrolusite, and the manganese contribution from other natural minerals at step 3 was less than $1 \%$ of the total manganese. However, the experimental value was much less than the calculated one. This observation strongly suggested a proportion of manganese released from pyrolusite at step 3 was readsorbed onto the surfaces of other phases. The predominant part of manganese was readsorbed onto humic acid and a lesser amount of manganese onto clay. The readsorbed manganese was brought into solution at steps 4 and 5 , so that the experimental values were greater than the calculated results.

Second, the readsorption and redistribution were explained in another way. If we compared the experimental and calculated values for most of the elements, it was not difficult to find a trend in elemental partitioning. Almost all the experimental values for steps 1-3 were smaller than the calculated ones, except for calcium and lead at step 3 . Contrastingly, the experimental values for most of the elements at steps 4 and 5 were greater than the calculated results. This fact definitely demonstrated that the trace elements of exchangeable, carbonate-bound and amorphous iron-manganese oxide-bound fractions could be transferred from solution to the other solid phases such as humic acid, crystalline iron oxides, and clay minerals during the sequential extraction, i.e., readsorption and redistribution occurred. Because humic acid can form relatively stable complexes with copper, manganese, nickel, zinc, lead, and vanadium, certain amounts of these elements released at the previous steps were readsorbed onto the humic acid. Afterwards, the humic acid was destroyed by $0.02 \mathrm{M} \mathrm{HNO}_{3}$ and $30 \% \mathrm{H}_{2} \mathrm{O}_{2}$, and the readsorbed elements were brought into solution again. This was why the experimental results were larger than the calculated values for the elements mentioned above. Quite similar reasons could be used to explain the results obtained at step 5 .

On the basis of the above study, one can reach a conclusion that readsorption and redistribution occur, although it is 
difficult to quantify the extent and to explain the mechanism clearly.

\section{CONCLUSION}

Based on the present study some conclusions can be drawn: (1) When the single natural mineral is used, Tessier's method is able to remove the trace elements bound to the particular geochemical phase at the appropriate stage. For example, calcite, pyrolusite, and humic acid were almost completely decomposed by $1 \mathrm{M} \mathrm{NaOAc}$ at pH 5, $0.04 \mathrm{M} \mathrm{NH}_{2}$ $\mathrm{OH} \cdot \mathrm{HCl}$ in $25 \% \mathrm{CH}_{3} \mathrm{COOH}$ and $30 \% \mathrm{H}_{2} \mathrm{O}_{2}-0.02 \mathrm{M} \mathrm{HNO}_{3}$, and 3.2 $\mathrm{M} \mathrm{NH}_{4} \mathrm{OAc}_{\text {in }} 20 \% \mathrm{HNO}_{3}$, respectively, at steps 2-4. Silicate residue can be decomposed by $\mathrm{HF}$ and aqua regia.

(2) When the model soil synthesized with several natural minerals and humic acid is used to examine the validity of Tessier's method for speciation analysis of trace elements, readsorption and redistribution of trace metals onto the remaining solid phases are quite evident. Various proportions of metals released from exchangeable, carbonate-bound, FeMn oxide-bound, and organic-bound fractions are readsorbed onto the other remaining solid phases.

(3) Since various materials and approaches were used in the literature, no direct comparison of readsorption and redistribution for trace elements during sequential extraction was available. Further study is required to search for the selective and specific extractants and to gain a better understanding of readsorption and redistribution processes.

\section{ACKNOWLEDGMENT}

The study was supported by the National Natural Science Foundation of China.

RECEIVED for review July 21, 1992. Accepted November $20,1992$. 